\title{
SUJETO PEDAGÓGICO, PODER Y DERECHO A LA EDUCACIÓN DESDE UNA PERSPECTIVA DECOLONIAL
}

\author{
Mónica Fernández* \\ Universidad Nacional de Quilmes, Argentina \\ mbfernandez@unq.edu.ar
}

Recibido: 2/08/2019 Aceptado: 25/02/2020

\section{Resumen}

En este sintético artículo queremos ocuparnos de un triple entramado: el sujeto, el poder y el derecho a la educación. Nos interesa dialogar brevemente sobre sujeto y poder, como íconos para pensar el derecho a la educación. Decimos que será un diálogo breve, porque comprendemos la complejidad, amplitud y polisemia que caracterizan a los dos términos principales: sujeto y poder. Pretendemos situarnos en aquellas miradas o perspectivas latinoamericanas, decoloniales y poscoloniales, que reflexionan desde la categoría de exterioridad. Nuestra tesis es la siguiente: el derecho a la educación visto desde una perspectiva decolonial, implica hablar desde una exterioridad que piensa un sujeto pedagógico situado y móvil al mismo tiempo. Trabajaremos principalmente con Dri y Dussel, aunque también incluiremos otros/as autores/as

Palabras clave: Derecho - Decolonialidad - Poder - Sujeto.

\begin{abstract}
In this synthetics article we want to deal with a triple entwine: the subject, the power and the right to education. We are interested in briefly discussing the subject and power, as icons to think about the right to education. We say that it will be a brief dialogue, because we understand the complexity, breadth and polysemy that characterize the two main terms: subject and power. We intend to place ourselves in those Latin American, decolonial and post-colonial perspectives, which meditate from the category of exteriority. Our thesis is the following: the right to education seen from a decolonial perspective, implies speaking from an exteriority that thinks of a pedagogical subject located and mobile at the same time. We will work mainly with Dri and Dussel, although we will also include other authors.
\end{abstract}

Keywords: Right - Decoloniality - Power - Subject.

\section{A modo de introducción}

En este sintético artículo queremos ocuparnos de un triple entramado: el sujeto, el poder y el derecho a la educación. Nos interesa dialogar brevemente sobre sobre sujeto y poder, como íconos para pensar el derecho a la educación. Decimos que será un diálogo breve, porque comprendemos la complejidad, amplitud y polisemia que caracterizan a los dos términos principales: sujeto y poder. Pretendemos situarnos en aquellas miradas o perspectivas latinoamericanas, decoloniales y poscoloniales, que reflexionan desde la categoría de exterioridad (lo que es marginal, los grupos

*Docente-Investigadora del Departamento de Ciencias Sociales: Integrante del Programa de Investigación "Discursos, prácticas e instituciones educativas". Directora del Proyecto de Investigación "Políticas Públicas de Inclusión Social, formación ético-política de la comunidad UNQ y Educación en Derechos Humanos. Miembro del Consejo Internacional de la Revista Latinoamericana de Derechos Humanos de la Universidad Nacional de Costa Rica. 
oprimidos e históricamente vulnerados, lo salvaje, lo folclórico, lo inmigrante, lo extranjero, lo mágico, lo pobre, lo hediondo, lo negro, lo excluido, etc.). Sin dejar de lado la epistemología y política de tipo occidental, los estudios decoloniales se caracterizan por utilizar fundamentaciones de tipo analógicas (Dussel), ecológicas o de traducción intercultural (Santos), y seminal o genético (Kusch).

Nuestra tesis es la siguiente: el derecho a la educación pensado desde una perspectiva decolonial implica hablar desde una exterioridad que piensa un sujeto pedagógico situado y móvil al mismo tiempo. Dicho de otro modo, la comunidad internacional (ONU), se refiere al derecho a la educación en infinidad de documentos internacionales, todos ellos discursean sobre la protección de los derechos humanos. Esta postura, lejos de ser una perspectiva universal, es un discurso que abarca la univocidad propia de la modernidad ilustrada y occidental, que generalmente se ocupa de producir teorías para que sean reproducidas en los márgenes hediondos (Kusch) de la negritud (Fanon), es decir, esas periferias situadas de la América Profunda en particular, y del sur colonizado en general. Así, ese modo discursivo de entender el derecho a la educación (ONU) es levantado por la mediocracia (Dussel) para poner en cabeza del cuerpo de estudiantes ese derecho, dejando fuera de la mirada a una de las partes involucradas en su exigencia: el profesorado y todo el personal educativo.

Para la tarea reflexiva, proponemos desarmar los conceptos eurocéntricos de sujeto y poder, y volver a armarlos desde una perspectiva latinoamericana, con el propósito de repensar el derecho a la educación. También dialogaremos sobre el concepto de alternativas pedagógicas, pensadas como un móvil para desaprender las concepciones educativas de tipo eurocéntricas. Con Rubén Dri (), reinterpretaremos los conceptos de sujeto y poder. Para el resto del artículo, tomaremos la mirada de Eduardo Rinesi sobre el derecho a la educación superior; de Adriana Puiggrós usaremos su noción de sujeto pedagógico; y con Hugo Biaggini, dialogaremos sintéticamente sobre el concepto de lo alternativo. Además, con la intención de provocar el diálogo reflexivo, nos ayudaremos con imágenes representativas de ese sujeto pedagógico situado y móvil que pretendemos caracterizar. Finalmente, sintetizaremos la perspectiva sobre la analéctica de Dussel.

\section{El sujeto como pro-yecto en movimiento subjetual: la perspectiva de Rubén Dri}

Desde Aristóteles para acá, mucho se ha dicho y escrito sobre el sujeto. Hay que advertir que, poder y sujeto, dada su polisemia, se dicen de muchas maneras. Aquí, diremos que un sujeto es siempre un poder y que éste simboliza, de alguna manera, también al primero. Siguiendo a Rubén Dri, proponemos utilizar cuatro interpretaciones sobre el sujeto, de las cuales, a medida que avancemos, podremos ir descubriendo su mimetización con la palabra poder. A nuestro autor no le interesa la filosofía como un pensamiento por el pensamiento mismo, sino que busca reinterpretar conceptos. Dicho por Dri, "En Hegel buscamos inspiración para reformular la racionalidad, el sujeto y el poder" (Dri, 2016, p.19); además, "las investigaciones de Marx, Engels, Rosa Luxemburgo, y en general, de los militantes y pensadores del socialismo, tiene su raíz en el texto hegeliano" (Dri, 2011, p. 85)

En primer lugar, el sujeto siempre es movimiento, fundamentalmente, porque tiene vida. Por eso mismo, el sujeto está en permanente transformación, es decir, está siendo. "El sujeto no es. La piedra es. El sujeto se hace, es un continuo hacerse. Un continuo ponerse” (Dri, 2016 , p. 26). Así, la constitución del sujeto podría simbolizarse en un movimiento circular que consta de dos extremos: ponerse y anteponerse. Como lo propio del sujeto es ponerse, en cada ponerse se constituye como sujeto. ¿Cómo opera este ponerse? Un claro ejemplo de la acción de ponerse es la interacción docente/estudiantes, justo ahí donde la trama de la praxis educativa se torna visible y nos muestra una forma de comunicación. En cada uno de esos modos de comunicarnos en el aula, somos sujetos porque nos ponemos. ¿Cómo es que ocurre este ponernos? Sucede mediante un doble movimiento de acción (obra, trabajo, gestión, servicio, labor, cometido, etc.) y reacción (rebeldía, indisciplina, insubordinación, rebelión, desobediencia, insurgencia, etc.). Este movimiento de acción y reacción que caracteriza al sujeto visualiza que se trata de un movimiento cargado de poder y resistencia. De ahí que, "Solamente el sujeto es dialéctico. Los objetos lo son en la medida en que son momentos del sujeto" (Dri, 2016, p. 27). Por eso, "Ser sujeto es hacerse sujeto" (Dri, 2016, p. 29).

Otra forma de comprender las vicisitudes del sujeto es mediante el movimiento de reconocimiento ${ }^{1}$, donde cada sujeto se reconoce y es reconocido. La simbología de este movimiento la encontramos en la clásica metáfora hegeliana: señor y siervo, que vendría siendo un movimiento subjetual (lo operatorio de un cuerpo físico y espiritual) de reconocernos y ser reconocidos/as. Desde que nacemos, comenzamos una lucha por el reconocimiento. "Sin esa lucha, sin lograr ser reconocido por otro sujeto al que al mismo tiempo reconoce, nunca llegaría a ser sujeto" (Dri, 2016, p. 26). En la dialéctica hegeliana, para dar lugar a la negación de la negación, uno de los extremos tiene que someterse voluntariamente, y ese extremo está simbolizado por el esclavo. Tras esa guerra dialéctico-alegórica, una de las partes se transforma (cambia, se modifica, se mueve, se proyecta) en objeto y la otra en sujeto.

Este movimiento transformativo, al ser objetual, siempre deja como resultado una relación de utilidad (de sometimiento, de opresión, de dominación, de uso). Aunque la relación entre sujetos es siempre asimétrica, para mirar hacia un horizonte subjetual (pleno, emancipado, con tendencia a lo

\footnotetext{
${ }^{1}$ Si bien reconocimiento (categoría muy significativa en la obra hegeliana), ser reconocido no es lo mismo que una relación de simetría, y lo que nos hace falta es esta segunda. No obstante, estamos frente a términos semejantes, aunque distintos; distinción en la que vale encarar una reflexión analógica. Volveremos más adelante sobre este intríngulis.
} 
igualitario), tiene que desaparecer el momento objetual característico de la relación sujeto-objeto (momento utilitario en el que la alteridad se transforma en objeto). Dicho de modo distinto, en esta inclinación hacia el reconocimiento entre sujetos siempre hay asimetrías: señor-siervo, madre y padrehijos e hijas, docentes-estudiantes, proletariado-capitalistas, dirección técnica-equipo, etc. Aunque en las relaciones entre sujetos siempre hay una tendencia objetualizante, ese movimiento forma parte de la creación de cada subjetualidad, porque "Efectivamente, la lucha es por el reconocimiento recíproco entre dos sujetos o autoconciencias" (Dri, 2011, p. 23), y ahí se daría el momento de subjetualidad. Pero en las instituciones (familia, educación, salud, trabajo, etc.) solemos participar de relaciones profundamente objetualizadas. Aquí nos interesa básicamente el problema educativo, fundamentalmente la relación pedagógica, y dentro de esta, la acción de escuchar atentamente a la parte que ha sido históricamente oprimida al interior de las instituciones.

Una tercera dialéctica del sujeto se vincula con el poder de crear y ser creado. Es cierto que nadie puede crearse a sí mismo en sentido biológico, pero crear un sujeto es una tarea distinta. En este camino, crearse creando, es uno de los modos que tenemos como sujetos para interpretar el mundo. Lo propio del sujeto libre es crear, porque cada quien se crea a sí mismo. En la versión cultural del capitalismo, dado que el proceso de creación siempre es enajenado, la marcha de crear y crearse se fetichiza. Crear algo para crearnos es un movimiento dialéctico, pero en el mundo capitalista, quien pone los recursos para que una alteridad se ocupe de crear algo, se lleva la creación de eso que no ha creado, porque se fetichiza la creación.

Pero hay una auto-creación personificada en el trabajo (creación) de un sujeto colectivo, entendido como acción de creación humana, donde los seres humanos no solo creamos cosas, sino que también creamos cultura (¿emancipación?). Dicho de otro modo, para ponernos como sujetos creadores y comunicantes, ambos extremos dialécticos (amo y esclavo, docente y estudiante, proletario y empresario, etc.) tenemos que liberarnos de la relación de objetualidad (utilidad). Dicho con Dri:

El camino de la realización del sujeto se abre por el lado del siervo mediante el trabajo formativo, o trabajo creativo, cuyo fruto es el mundo de la cultura, la eticidad o segunda naturaleza ${ }^{2}$, en la que se reconoce como sujeto. De esa manera, se independiza, y pasa a proclamar su libertad ${ }^{3}$ (Dri, 2011, p. 44)

No obstante, hay que advertir que la posibilidad emancipatoria nunca se da plenamente, porque en toda relación subjetiva hay asimetrías, pero éstas siempre son intercambiables, porque cada sujeto puede realizar su propia interpretación y ponerse como sujeto. En este sentido, sin una relación de alteridad subjetualizante: libre, creadora, comunitaria, solidaria, tendremos pocas posibilidades para reconocernos mutuamente como sujetos y sujetas libres.

En cuarto lugar, sabemos que el sujeto (individual o colectivo) está atravesado por una trama de relaciones sociales que son idilios intersubjetivos. Así, el sujeto siempre es un conjunto interconectado de relaciones. Dijimos que la realidad del sujeto es ponerse, crearse, reconocerse y comunicarse, y todos estos movimientos son realizados porque se cimientan en un ensamble de relaciones sociales. Dri lo dice del siguiente modo:

El sujeto es esencialmente intersubjetivo, es un inter-sujeto, un co-jeto, o, empleando una terminología más sociológica, un "ensamble de relaciones sociales ${ }^{4}$, como dice Marx en las tesis sobre Feuerbach (Dri, 2011, pp. 58-59)

Para que podamos reconocernos mutuamente, es necesario que desaparezca la relación de utilidad (de uso, de alienación, de opresión, de enajenación). Porque la condición de dejarnos mover por una otredad es propia de la relación de utilidad (capitalista y neoliberal). Eliminar ese momento objetual, que siempre es dominación, es un poder para reconocernos de sujeto a sujeto, y esto está encarnado en el horizonte de la alteridad analéctica. Para encontrar este horizonte, tenemos que tomar distancia de esa relación utilitaria (objetual) que siempre es dominación.

Como sujetos y sujetas, y dada nuestra huella colectiva, tenemos una historia que solemos explorar para reconsiderarla y comenzar a construir un nuevo pro-yecto. Además, como sujetos, no podemos ponernos sin anteponernos. Esto implica que cada ponerse se corresponde con un anteponerse que se construye, entre otras cosas, en función de un recuerdo o de una auto-memorización. Si la acción de recordarse es anteponerse, la memoria de un relato sería una dialéctica propia de la operación constitutiva de un sujeto. Proyectarnos en el mundo sería una tarea imposible sin relatarnos; porque el tipo de sujeto que cada quien construye se funda en el tipo de memoria que ha colaborado para su

\footnotetext{
${ }^{2} Y$ es claro que, en Hegel, esa segunda naturaleza es propia de la formación, o Bildung, que vendría siendo la educación, como segundo nacimiento (idea que toma de Kant y éste de Rousseau).

${ }^{3}$ Hay que tener presente que libertad no es lo mismo que emancipación, puesto que la segunda es algo así como un dejar de ser infante, o alcanzar la mayoría de edad, lo que nos pone en el ámbito de las instituciones per se, mientras que la libertad es un asunto de conciencia cultural.

${ }^{4}$ Cuando en las citas textuales escribimos comillas y cursivas, ambas corresponden a la versión original de cada texto citado.
} 
constitución. En este camino, toda una vida es algo así como una memoria del ponerse, que siempre es una forma de anteponerse.

En esta memoria del anteponerse aparece un claro nexo colectivo, porque un pueblo, comunidad, aula, escuela, colectivo social, o cualquier otra forma grupal organizada de ponerse, es un sujeto colectivo que se puede poner porque ya ha pasado por un anteponerse: tiene una historia. Pero como la historia suele reconsiderarse según cada pro-yecto, y éstos son siempre realizados de modo colectivo, recuperar la historia mediante distintas versiones de un mismo suceso, es una forma de ponerse. Precisamente, ese ponernos en un pro-yecto distinto (analógico), podría estar dado por la posibilidad del examen histórico. Vamos a decirlo con palabras de Dri, "Toda insurrección popular instaura el espacio y el instante de la gran utopía, es decir, de las grandes, inconmensurables ansias, anhelos, deseos, que animan al sujeto popular" (Dri, 2011, p. 73).

Todas las insurrecciones sociales de la historia nos pusieron en ese lugar de la libertad; en ese lugar en que nos pudimos deshacer de las cadenas opresivas. Pero, después del asalto insurgente ¿qué hacemos con esa libertad, con esa liberación del yugo opresivo del poder instituido? Después de la locura revolucionaria nos damos cuenta que algo nos faltó. "Precisamente para encontrar una respuesta que nos oriente debemos prestar atención a la diferencia entre utopía y proyecto" (Dri, 2011, p. 75). Se trata de dos momentos vinculados entre sí, pero distintos (analécticos) que tenemos que tener presentes: la utopía (revolución sin más, basta de opresión, ya no seremos seres esclavizados) y el pro-yecto (metodología trazada, planificada, pensada, dialogada) que nos muestra el camino para cumplir, realizar, concretar nuestra libertad)

En suma, acción y reacción, como movimientos del ponernos y anteponernos en la estela de una reconstrucción histórica de cada proyecto (individual o colectivo), nos muestra que tenemos el poder de construirnos como sujeto, y que somos sujetos porque nos creamos como tales. Dado que los diversos movimientos que caracterizan al sujeto: ponerse y anteponerse, reconocer y reconocerse, crear y crearse, proyectar y proyectarse, construyen poder; así también, "Construirse como sujeto es construir poder" (Dri, 2002, p. 91) Así, crearse como sujeto es lo mismo que crear poder; y construir poder es un modo de construirse como sujeto y viceversa. Para crear un poder colectivo necesitamos crear conciencia desde abajo, y este tipo de creación es, de suyo, una praxis pedagógica. Para construir poder como sujeto colectivo, necesitamos un pro-yecto en común, basado en un relato en común. Que el relato sea común, de ninguna manera quiere decir idéntico o igual.

\section{El sujeto pedagógico, las alternativas educativas y el derecho a la educación}

Adriana Puiggrós (1990) siguiendo las enseñanzas de Freire y Rodríguez, dice que un sujeto pedagógico representa un vínculo entre quien enseña y quien aprende.

Para que ese sujeto pedagógico fluya (cambie, se mueva, se transforme), tiene que existir algo que medie entre ambos. Podríamos llamar a ese algo que media entre los extremos del sujeto pedagógico, el contenido temático. Este contenido podría estar explicitado en un documento curricular, o no, pero siempre habrá tres elementos en juego cuando hablamos del sujeto pedagógico. En este sentido, está claro que, en esa tríada, se juega y cobra vida el derecho a la educación, fundamentalmente, porque cualquier práctica educativa produce un tipo de sujeto pedagógico.

Así, esa cosa que es un sujeto puede cambiar porque está siendo afectada por algo externo (supongamos el derecho a la educación), pero para que ese derecho afecte desde dentro, cada extremo del sujeto pedagógico, tiene que apropiárselo como un valor. Entre el afuera y el adentro del sujeto afectado se debate el derecho a la educación, ocupando el lugar del mediador entre los extremos del sujeto. Aquí entonces tenemos un primer indicio, el sujeto que cambia o permanece, y el derecho a la educación, que influye en ese cambio.

Recordando las enseñanzas de Marx, el sujeto, contra toda la teoría cartesiana que individualiza la subjetividad, siempre es un ente colectivo. El inconveniente es que ese sujeto, en este caso el sujeto proletario, necesita tomar conciencia de la significatividad de su lugar en la producción de un bien, sobre todo, para reconocer y defender su clase.

Entonces, ¿cómo lograr que el sujeto pedagógico se apropie del valor del derecho a la educación, es decir, que se pregunte sobre ese valor? Parece de suma importancia poder deliberar con la comunidad educativa sobre este punto, fundamentalmente, porque el derecho a la educación, suele ser el latiguillo más importante que la mediocracia utiliza para denostar el derecho a huelga; además de reconocer en la manifestación ciudadana, el monstruo de la crisis de la educación.

Para desenredar y empezar a tejer otras redes dialógicas sobre el lazo inconmovible que existe entre docentes y estudiantes cuando hacemos referencia al derecho a la educación, diremos que ninguno de los dos extremos existe sin el otro. Ninguno de los dos extremos opera en soledad. Ninguno de los dos extremos disfruta de su derecho a la educación si la otra parte no lo asume como valor propio. Por eso, el derecho a la educación es el motor del sujeto pedagógico. Lo más lamentable es que el nivel reproductivo de la cultura hegemónica representada por los medios de comunicación, continúa dominando el discurso pedagógico que moviliza a parte de la comunidad educativa. Aunque siempre está prendida la llama de la esperanza. Por eso, el sujeto pedagógico que defiende el derecho a la educación, lejos de ser algo perteneciente a uno de los extremos del sujeto pedagógico, está siendo y viviendo en la imagen que sigue. Acá parece asomar una punta del ovillo, que podríamos llamar, si se quiere: alternativa pedagógica. 
Podría decirse que la pedagogía latinoamericana, en ese marco eurocentrista al que nos ha acostumbrado la tradición occidental, vendría siendo una suerte de alternativa pedagógica. Aquí también pretendemos desarmar el rompecabezas. En línea con un artículo de Biggini (2009), una alternativa es algo así como una serie de sucesos éticos, políticos y económicos, con pretensión de presentarse socialmente como herramientas contra hegemónicas. De este modo, "que una cosa cualquiera se muestre como alternativa, no puede dejar de ser: crítico, abierto, emancipatorio" (Biggini, 2009, p.36).

A la serie de acontecimientos políticos de la alternativa anterior, podríamos sumarle con Puiggrós (1994), la utopía y la esperanza. Aquí, el punto central de la discusión serían los nuevos sujetos pedagógicos. Para Puiggrós, la alternativa pedagógica sería una propuesta educativa de tipo prospectiva y que considere las relaciones de poder entre diferentes grupos, como una propuesta abierta a diversas posibilidades. De este modo, una alternativa es una categoría construida para visibilizar contextualizadamente un tema-problema.

Aunque se pueden incluir aquí otras experiencias educativas exitosas, la pedagogía latinoamericana nos trae alternativas para dialogar sobre el sujeto pedagógico. Desde Martí hasta Freire ${ }^{5}$, pasando por otros educadores y otras educadoras, vemos que el derecho a la educación vive en el sujeto pedagógico. En la pedagogía latinoamericana, es decir, en el discurso de sus referentes, se comprende que el valor del derecho a la educación no está en las normas que lo reconocen como tal (léase, por ejemplo, la Organización de las Naciones Unidas) sino en la mediación pedagógica que se da entre ambos extremos del sujeto pedagógico. Entonces, ¿de qué derecho a la educación hablamos?

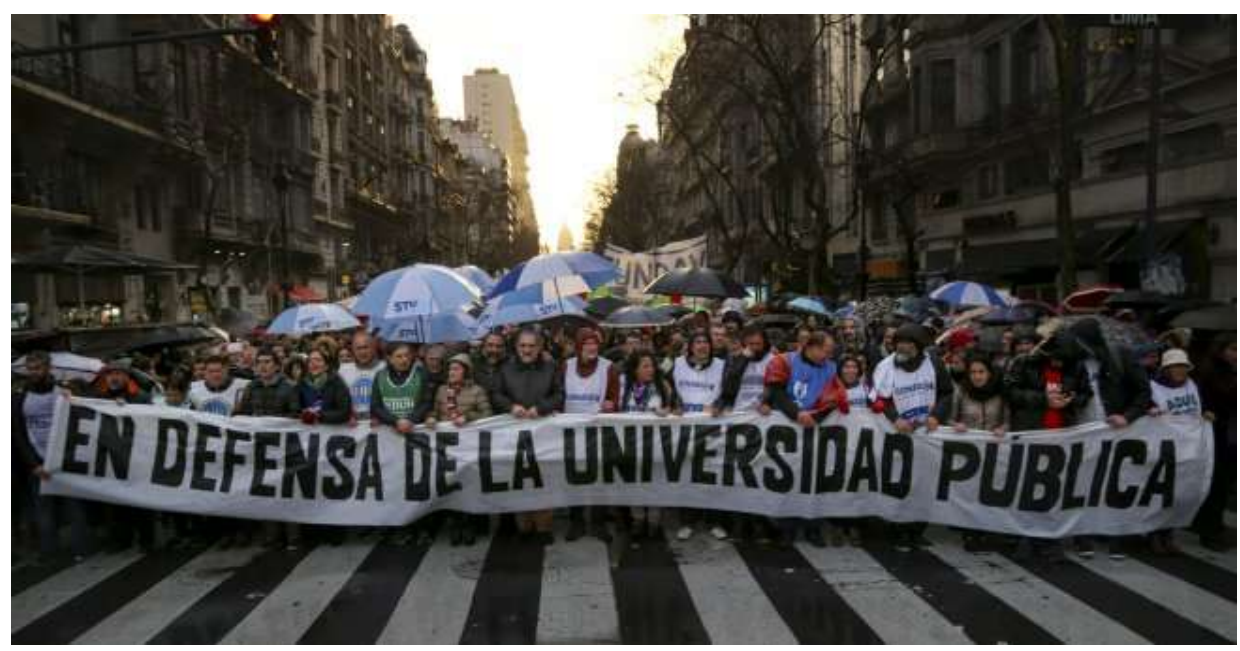

Imagen No 1 (Fuente: https://images.app.goo.gl/jfsM8eqKuvXrDVvj9)

En la imagen, ¿está el derecho a la educación encarnado en su sujeto pedagógico? En un artículo de Rinesi (2014) hallamos una respuesta posible. El autor dice que, una vez que la escuela secundaria ha adquirido carácter obligatorio, la Universidad se transforma en un derecho. Es que mientras la enseñanza primaria era obligatoria, la escuela secundaria se entendía como una alternativa educativa, un lujo y el paso certificante a otra suntuosidad, que vendría a estar representado por la Universidad. Rinesi lo dice así, "solo cuando la educación secundaria empieza a ser pensada como una obligación, la educación universitaria puede empezar a ser pensada como un derecho" (Rinesi, 2014, p.10) ${ }^{6}$. La comunidad universitaria muestra a diario que el derecho a la educación está representado por un sujeto pedagógico que, al igual que el sujeto proletario, es un ente colectivo que trabaja y lucha por una educación de calidad. Una educación de calidad es el enclave del derecho a la educación.

\section{Sujeto pedagógico y praxis educativa: la analéctica de Enrique Dussel}

Así como existen muchos modos de decir sujeto, también hay muchas maneras de decir praxis. La praxis tiene que ver con la actividad, con el hacer, decir, escuchar, actuar. Aunque actualmente la palabra praxis suele leerse como mera práctica, por su polisemia y movimientos de transformación, diremos que se trata de un término pluriversal. Así, aunque en sentido lato la palabra praxis remite a la acción humana, en sentido griego, ese hacer de la praxis, va mucho más allá de una simple acción mecánica.

\footnotetext{
${ }^{5}$ Simón Rodríguez, José Vasconcelos, José Mariátegui, Jesualdo Sosa y Gabriela Mistral, entre otros defensores de una educación popular, pluralista e inclusiva.

${ }^{6}$ La cursiva corresponde al original.
} 
La obra de Dussel es fecunda ${ }^{7}$ y basada en una praxis específica: la pedagógica. Nos interesa abordar sucintamente su mirada analéctica. En este sentido, Para una ética de la liberación latinoamericana, nos piensa, nos aguijonea, nos convoca, y nos interpela, desde varios campos del saber.

Lo que es característico del planteo metodológico de la filosofía originaria de Dussel (años setenta del siglo pasado), vendría siendo una interpretación de la dialéctica materialista de Marx, en comunión con la perspectiva ética de Levinas ${ }^{8}$. Para Dussel, enemigo intelectual de la filosofía de $\mathrm{Hegel}^{9}$, el pensamiento de la totalidad (unívoco, abismal, circular, universalizado, único), deja fuera de foco todo lo que es exterior a esa mismidad. Para Dussel, la dialéctica hegeliana piensa la vida como totalidad absoluta, es decir, es un pensar que piensa el pensamiento. De modo similar, rechaza la totalidad heideggeriana, entendida como comprensión del ser para la muerte, ontologizado y casi sin vida comunitaria, porque está perdido en el mundo de todo el mundo. Este modo de pensar es logológico (pensar que se piensa a sí mismo) y egológico (yo pienso), en el cual, el hombre y la mujer común, estarían excluidos y excluidas de esa dialéctica abstracta del absolutismo de Hegel y la hermenéutica de Heidegger.

En contra de ese desarraigo filosófico, la filosofía situada de Dussel pretende recuperar la base histórica de la realidad: la praxis. Para lograrlo, nuestro autor concibe el método analéctico, que nos enseña a recuperar las concepciones más vitales del mundo de la vida. En este sentido, habría dos dialécticas que nuestro filósofo busca des-truir, o desestabilizar para construir una novedad: la analéctica. Dicho con Dussel, la analéctica:

Nos propone mostrar cómo más allá del pensar dialéctico ontológico y la Identidad divina del fin de la historia y el saber hegeliano (imposible y supremamente veleidoso: ya que intenta lo imposible) se encuentra todavía un momento antropológico que permite afirmar un nuevo ámbito para el pensar filosófico, meta-físico, ético o alternativo (Dussel, 2017 [1973], p. 156).

Ese pensar que se piensa a sí mismo (entelequia) y abre la puerta a la abstracción totalitaria, fue viciando la realidad, y contaminó la praxis comunitaria; lo que fundó un alejamiento del pensar filosófico sobre la vida, anestesiando la sensibilidad ética. El propósito del método analéctico es mostrarnos un camino para superar esa entelequia del pensamiento ontológico al que también Lévinas está atado, dada su perspectiva eurocéntrica.

Para referirse al tema de la escucha o ponerse a oír a la alteridad, Dussel declara que no recurrirá a la filosofía griega, sino que invocará al pensamiento de otras culturas más antiguas. La praxis que le interesa analizar es la de los pueblos egipcios de tradición judía. En este marco, para sentirnos interpelados por una alteridad desde un escuchar atento, hay que saber oír. "Se trata siempre de una palabra que llama, de una voz que interpela desde más allá del orden de la visión, trans-ontológica, pero que es efectiva solo si hay un oído que sepa oír" (Dussel, 2017 [1973], p. 53). El punto es que, "Oír la voz-del-otro significa una apertura ética, un exponerse por el otro que sobrepasa la mera apertura ontológica" (Dussel, 2017 [1973], p. 53) ${ }^{10}$. Así, hay una dialéctica que se conecta mediante dos momentos ónticos: la voz y el oído, que son una unidad inseparable, porque la primera es el medio que sensibiliza el mundo ético, y eso se logra mediante la acción del segundo. "La "conciencia ética" es entonces oír-la-voz-del-otro; voz o palabra que exige justicia, que exige su derecho..." (Dussel, 2017 [1973], p. 57).

No se trata de una escucha basada en la obediencia, tal y como lo ha entendido la tradición pedagógica occidental, aquella acción educativa que oprime o aliena; sino de un acto de oír atentamente, en el que la voz de la otredad, en una praxis interpelante, nos permite interpretar lo injusto. Pero ¿qué es la justicia?, ¿de qué tipo de justicia nos habla la praxis pedagógica latinoamericana? Bien, la justicia es el acto de ponernos y anteponernos en un pro-yecto común, una aventura distinta a la que nos trae la mirada utópica. Ese pro-yecto común, pensado como poder comunitario instituyente, nos permite participar de un tipo de praxis pedagógica pluriversal.

El instrumento o técnica de investigación-acción del método analéctico, está puesto en el ejercicio de extremar las medidas de comunicación comunitaria, mediante la puesta en marcha de un tipo de escucha atenta, que nos permita sentirnos interpelados ${ }^{11}$ por la voz de esas poblaciones oprimidas

\footnotetext{
${ }^{7}$ Un panorama rápido por la obra más significativa, por lo menos para lo que aquí nos ocupa, es decir Para una ética de la liberación latinoamericana, son los siguientes libros, a saber: (Dussel,16 tesis de economía política. Interpretación filosófica, 2014), también (Dussel, 14 tesis de ética. Hacia la esencia del pensamiento crítico, 2016) y (Dussel, 20 Tesis de Política, 2006). Estas tres obras, poseen algunas modificaciones realizadas por el autor, producto de sus posteriores investigaciones. En ellas, se puede consultar lo que podríamos llamar, la tríada programática de la ética de la liberación latinoamericana.

${ }^{8}$ Posteriormente le adicionará la teoría de la comunicación ética o ética discursiva desarrollada por Aple y mejorada por Habermas.

${ }^{9}$ En este punto en donde la obra de Dussel entra en tensión con la caracterización que hace Dri, aunque ambos autores trabajan en torno a la praxis liberadora latinoamericana.

${ }_{10}$ Es claro que está discutiendo con Heidegger, porque para Dussel, el método del filósofo alemán habla de la apertura ontológica, olvidándose u omitiendo la cuestión ética.

${ }^{11}$ Lo que de ninguna manera implica que podamos comprenderlo, pero la opción del saber oír es, de suyo, una praxis pedagógica liberadora.
} 
que han sido olvidadas por el pensar occidental-moderno. Es que, "Este pensar ana-lectico, porque parte de la revelación del Otro y piensa su palabra, es la filosofía latinoamericana, única y nueva, la primera realmente postmoderna y superadora de la europeidad" (Dussel, 2017 [1973], p. 162).

La característica fundamental del método es el saber oír. Un tema recurrente en la pedagogía freireana, y casi sin tratamiento en la formación del profesorado, dado el claro estilo académico de una docencia que habla y un estudiantado que toma nota. La escucha atenta es de suyo una praxis pedagógica liberadora, que bien podría ${ }^{12}$ acompañarnos en las reflexiones educativas, como un posible camino para reconocernos mutuamente y exigir justicia para la historia de la opresión latinoamericana. De algún modo, la metodología del oír con atención, es un claro camino para activar algo que viene cayendo en desuso gracias a la resistencia de los métodos educativos utilizados en todos los niveles educativos ${ }^{13}$ y la excesiva mediocracia: la conciencia de clase. En definitiva, "El saber-oír es el momento constitutivo del método mismo; es el momento discipular del filosofar; es la condición de posibilidad del saberinterpretar para saber-servir (la erótica, la pedagógica, la política, la teológica)" (Dussel, 2017 [1973], p. 163).

La analéctica dusseliana nos convoca a dialogar sobre un modo de pensar auténtico, en el sentido de comprometido y responsable. Por eso, lejos de ser una interpretación basada en el ejercicio teórico, nos invita a comunicarnos desde una interpelación encarnada en la palabra de la otredad (exterioridad). Porque la esencia del hombre y la mujer es la comunidad, "lo supremamente sensible es otro hombre [y otra mujer. Por eso] El tú sensible es exterioridad de la razón, es existencia real" (Dussel, 2017 [1973], p. 58). Pobreza, explotación, opresión, ocultamiento del origen de la riqueza y el capital, invisibilización de la voz de la otredad, entre otros avatares del mundo latinoamericano o Abya Yala, ha sido nuestra herida de muerte, provocada por la historia de la colonización, el capitalismo y su consecuente patriarcado.

Lo que busca la analéctica es contraponer esa abstracción absolutista y totalitaria de la filosofía eurocéntrica, con el fin de poner vida a la realidad latinoamericana. Pero, ¿cuál es el medio que nos permitiría reconsiderar o recomponer esa totalización del pensar? Ese elemento material (porque tiene vida, porque es una voluntad de vivir) está encarnado en la figura de la otredad, fundamentalmente en su voz y su rostro interpelantes. En este sentido, la otredad que piensa Dussel, a diferencia de la ética levinasiana, es una alteridad antropológica; porque esos grupos oprimidos, tienen una historia, una vida, sienten, sufren, padecen. En esta metodología, la otredad se me revela en función de sus carencias, su dolor, su desgarramiento, su finitud. La ética antropológica de la exterioridad que nos trae Dussel, se ocupa de las injusticias, porque saber oír atentamente para permitirnos sentir la interpelación, es de suyo, un proceso analéctico. La palabra de la otredad irrumpe desde un más allá o más arriba (ana y aná), nos invade desde un mundo análogo, pero dis-tinto. "Es decir, la revelación del Otro abre el pro-yecto ontológico pasado, de la Patria vieja, de la dominación y alienación del Otro como "lo otro", al pro-yecto liberador" (Dussel, 2017 [1973], p. 169).

Entonces, en el caso del sujeto pedagógico y la praxis educativa ¿qué significa dialogar analécticamente? ¿Dónde y cuándo tiene lugar esta praxis educativa analéctica? Este tipo de metodología libertaria, ¿podría aplicarse en un aula de cualquier institución educativa o solo es viable en talleres para comunidades insertas en procesos educativos aplicados por los movimientos sociales? La analéctica trata sobre un pensar dialogante y dialógico sobre la exterioridad, que es todo ese caudal humano que no entra en las filosofías totalizantes de corte eurocéntrico. La praxis analéctica es un camino hacia una justicia. En este sentido, justicia no es solamente un camino jurídico, tampoco uno de los poderes del Estado. Justicia no hace alusión al juicio de las instituciones de las sociedades civiles. Justicia en sentido analéctico no es ninguna de las opciones anteriores, pero las incluye a todas. Porque la palabra justicia está en cada rostro y cada de esa humanidad históricamente negada a la población de América Latina y otras geografías del sur. Pero, ¿quiénes son esas víctimas?, ¿las podemos reconocer fácilmente?

De una parte, víctimas son aquellas poblaciones cuya cultura, en el sentido antropológico del término, ha sido negada por el colonialismo, el capitalismo y el patriarcado. Entre las comunidades afectadas por el universalismo totalizante se cuentan: poblaciones originarias, mestizas, marginadas, migrantes, mujeres, la infancia y la adolescencia, la clase trabajadora, las personas con discapacidad, las personas adultas mayores, etc. De otra parte, cualquier relación pedagógica, dado su carácter asimétrico, suele estar expuesta a formatos opresivos, lo que nos pone en un lugar más dificultoso para reconocer ese camino a la praxis analéctica.

Una praxis auténtica (responsable, comprometida) es analéctica (mira las semejanzas en la distinción) porque hace foco en la capacidad de escuchar atentamente a partir de un cambio de roles, pensando específicamente en la vida del aula. Para lograr que este tipo de ejercicio dialógico se lleve a cabo, Dussel propone un enroque en lo que hace al lugar que ocupa quien oficia de filósofo o filósofa, como figura central de la pedagógica. Se trata de un circuito pedagógico que, antes que nada, es de

\footnotetext{
${ }^{12}$ Aunque existen excepciones, el sistema educativo es más un monólogo ejercido por el profesorado que un diálogo entre los extremos del sujeto pedagógico.

${ }^{13}$ Aunque existen excepciones, el sistema educativo es más un monólogo ejercido por el profesorado que un diálogo entre os extremos del sujeto pedagógico.
} 
discipulado, porque es el momento de la escucha interpelante para considerar la palabra de la otredad como semejante a la de mi mundo, pero distinta. Ponernos en el lugar del que aprende nos permitirá interpretar la voz de la alteridad, en un circuito analéctico que es el medio específico para la liberación, porque la filosofía, antes que saber supremo, es una pedagógica discipular.

\section{A modo de telón}

En función de los diversos movimientos que caracterizan al sujeto y al poder (ponerse y anteponerse, reconocer y reconocerse, crear y crearse) necesitamos crear conciencia desde abajo, es decir liberarnos de la colonialidad que crea el capitalismo y el patriarcado, y crear un poder colectivo. Porque crearse como sujeto es lo mismo que crear poder, y construir poder es un modo de construirse como sujeto y viceversa. Para construir poder como sujeto colectivo necesitamos un pro-yecto en común. Se trata de una narrativa enriquecida desde categorías analógicas (pluriversales), que vendría siendo una praxis de liberación.

El sujeto pedagógico define a la praxis educativa que, lejos de ser algo perteneciente a uno de los extremos (docente-estudiante), está siendo y viviendo en la interacción áulica. Las comunidades educativas que se manifiestan (se ponen y anteponen, para crear y reconocerse mutuamente) muestran que la praxis educativa es un sujeto pedagógico combinado, situado y móvil. Un cuerpo colectivo que trabaja y lucha por una praxis liberadora en cada rebelión o insurgencia en la que se manifiesta. Aquí es donde vive, se descubre, se siente, se comprende...en qué contexto habita el derecho a la educación.

Con las concepciones que nos presenta Dri sobre el sujeto, dijimos que la liberación implica crear conciencia desde abajo mediante la creación de un pro-yecto en común; pero no dimos detalles sobre la metodología para lograrlo, porque esta tarea la trajimos de la mano de Dussel ${ }^{14}$. Con este último, tratamos de relatar y recorrer la pedagógica que habita en el transcurso o trayecto liberador. La pedagógica posee una relación analógica (semejante pero distinta) respecto de la pedagogía, puesto que, al contrario de las recomendaciones de la segunda, para la primera, quien comienza su tarea de escuchante atento ocupando el lugar de aprendiente, es el extremo del sujeto pedagógico que oficiaría de enseñante. De algún modo, que la docencia se ponga en el lugar de estudiante, implica otorgarle un poder que, para la pedagógica, esa alteridad tiene antropológicamente.

Pero, ¿cuál es el fundamento de este poder de la voz tan originario que se manifiesta en el movimiento de la praxis educativa como pedagógica? Si entendemos a la educación como un acto político, ¿cuál es el principio, razón o fundamento, para que nuestra región continúe estando oprimida por la cultura colonial, capitalista y patriarcal? Dussel considera que hay un entramado de corrupción entre el poder de la sociedad civil y el poder la sociedad política. Por eso el poder del Estado se fetichiza. Porque «La corrupción es doble: del gobernante que se cree sede soberana del poder, y de la comunidad política que se lo permite, que lo consiente, que se torna servil en lugar de ser actora de la construcción de lo político» (Dussel, 2006, p. 14). Dussel señala que existe una interpretación errónea sobre el poder originario de las comunidades (atadas a la tierra y a la organización social solidaria), que venimos acarreando desde las conceptualizaciones políticas de la modernidad occidental. Un poder que, ante la delegación o el consentimiento de la política contractual de la modernidad, fetichizó ese poder originario hasta transformarlo en dominación. Lo que caracteriza a los pueblos originarios es la voluntad de vivir, y esa voluntad de vida se lleva a cabo desde una organización comunitaria. En estas organizaciones sociales, cada miembro participa de la comunidad de vida.

Lo cierto es que, la analéctica no es un diálogo como cualquier otro, sino que es un diálogo franco, honesto y de cara a un futuro distinto que nace a partir de una interpelación ética originaria, porque "la analéctica es una pedagógica de la liberación, una ética primeramente antropológica o una meta-física histórica" (Dussel, 1973, p. 116). Ese encuentro virtuoso, supone la necesidad de alimentar la dis-tinción del Otro y la Otra, lo que nos pone de cara a la relación educativa, es decir a la praxis pedagógica analéctica, porque "es superadora de la dialéctica desde la pro-vocación al servicio en la justicia que nos exige el pueblo latinoamericano en su camino de liberación" (Dussel, 1973, p. 117). Esta praxis se funda en la capacidad de estimular la distinción de la Otra y el Otro por el encuentro libre y honesto, con pretensión de justicia y simetría. El pluriverso es posible porque hay una comunidad real de vida, una comunidad vital llena de experiencias, dichas, saberes, música, fiestas, desencuentros, pérdidas, desdicha, creaciones, es que

\footnotetext{
${ }^{14}$ Dussel y Dri representan un corte epistemológico entre el marxismo tradicional y las diversas corrientes filosóficas europeo-norteamericanas. Ambos están atravesados por esa categoría de categorías (la praxis latinoamericana) que les ha permitido indicar la mayoría de edad del pueblo latinoamericano para poder, así, pro-yectar un futuro distinto al marcado por la cultura colonial. Ambos han formulado y reformulado, desde sus diversos diálogos con la filosofía crítica del centro coincidiendo, curiosamente, en distintas lecturas de Hegel y Marx, que han sido los padres de esta categoría. Sin embargo, aunque hay claras similitudes (un discurso epocal y geopolítico) también hay distinciones, que necesitan describirse con más tiempo y espacio.
} 
Cada rostro en el cara-a-cara es igualmente la epifanía de una familia, de una clase, de un pueblo, de una época de la humanidad y de la humanidad misma por entero, y, más aún, del Otro [y la Otra] absoluto (Dussel, 1973, p. 122).

Pero, ¿cómo se alimenta la dis-tinción de una vida nueva, de una vida Otra? ¿Cómo se alienta a las personas a ser sujetos y no objetos, pero además pensando en que ellas y ellos también son responsables de alimentar y cuidar la distinción y la novedad? ¿Qué hay más allá de la relación dialéctica entre docente-estudiante? ¿Cómo hacer crecer la alteridad comunicativa en simetría, es decir, semejante? ¿Cómo es que comenzamos a tejer este pluriverso desde la escucha atenta de justicia? ¿Cómo alentamos el pluriverso desde los contextos de sometimiento? ${ }^{15}$. Lo primero que tenemos que tener presente es que, "El filósofo ético debe descender de su oligarquía cultural académica y universitaria, para saber -oír la voz que viene del más allá, desde lo alto (aná), desde la exterioridad de la dominación" (Dussel, 1973, p.124). Se trata en principio de oír una revelación que pro-voca para luego poder verificar la palabra ${ }^{16} \mathrm{y}$, con esa pro-vocación, iniciar la aventura de la interpretación del mundo cotidiano de quien oficia de hablante (magisterio primero, discipulado después).

Así, se visualiza que el paradigma dusseliano del pluriverso analógico es la humanidad misma. El pluriverso nos habla de una universalidad analógica, unificada en la diversidad de sus partes integrantes, que es "una sola Patria universal en la libertad solidaria de las partes" (Dussel, 1973, p. 135). Es decir, que se trata de una humanidad cuyo futuro está en construcción. Un futuro donde podamos prescindir de hablar de las naciones coloniales, es decir, periféricas y sometidas. Este pluriverso implica una posición de similitud en la dis-tinción de cada nación, de cada pueblo, para participar en un concierto polifónico que ofrezca las mejores expresiones en el servicio común de la vida humana. Este radicalismo categorial y metodológico ha sido planteado por Enrique Dussel, quien representa el intento de lograr un discurso mundial por la simetría donde las culturas dejan de ser entendidas como sustancias y pasen a comprenderse como sujetos. Pero más allá de eso, como una comunidad de comunidades donde realmente los conocimientos, pensamientos y experiencias, puedan llevarnos a nuestro estadio civilizatorio, el de la praxis pedagógica pluriversal, que trasciende el aula, aunque por supuesto, la incluye necesariamente.

\section{Referencias bibliográficas}

Biagini, H. (2009). El pensamiento alternativo y sus variables temáticas. En: Revista Marplatense de Filosofía, pp. 35-40.

Cortina, A. (2000 [1986]). Ética Mínima. Introducción a la Filosofía Práctica. Madrid: Tecnos.

Dri, R. (2002). Racionalidad, sujeto y poder. Irradiaciones de la fenomenología del espíritu. Buenos Aires: Biblos.

Dri, R. (2011). Hegelianas. Irradiaciones de la fenomenología del espíritu. Buenos Aires: Biblos.

Dri, R. (2016). Hegel y la lógica de la liberación. La dialéctica del sujeto objeto. Buenos Aires: Biblos.

Dussel, E. (1973). El método analéctico y la filosofía latinamericana. En: Nuevo Mundo Tomo $3 N^{\circ} 1$ EneroJunio, pp.116-135.

Dussel, E. (2006). 20 Tesis de Política. Mexico Ciudad: Siglo XXI

Dussel, E. (2017 [1973]). Para una ética de la liberación latinoamericana. México Ciudad: Siglo XXI.

Dussel, E. (2017 [1973]). Para una ética de la liberación latinoamericana. Tomo II. México Ciudad: Siglo XXI.

Puiggrós, A. (1990). Sujetos, disciplina y crurriculum, en los orígenes del sistema educativo argentino. Buenos Aires: Galerna.

Puiggrós, A. (1994). Sobre las alternativas pedagógicas. En: A. y. Puiggrós, Alternativas pedagógicas, sujetos y prospectivas de la educación en América Latina, pp. 271-298. Buenos Aires: Miño y Dávila.

Rinesi, E. (2014). La Universidad como derecho. Política Universitaria IEC CONADU, pp. 8-14.

\footnotetext{
${ }^{15}$ Las preguntas son a modo de provocación dialógica, puesto que intentar responderlas, amerita un trabajo aparte

16 Vale aquí anotar una diferencia fundamental que vamos a poner con Dussel, "El logos es unívoco; la dabar es análoga" (Dussel, 1973, p. 124). El primer término (logos) es la traducción de la segunda (dabar), que es una palabra que proviene de la lengua hebrea y que indica que esa palabra nos con-voca (o mejor, nos com-boca), desde el oír atentamente (desde un más allá) con el fin de interpelarnos.
} 